Provided for non-commercial research and education use. Not for reproduction, distribution or commercial use.

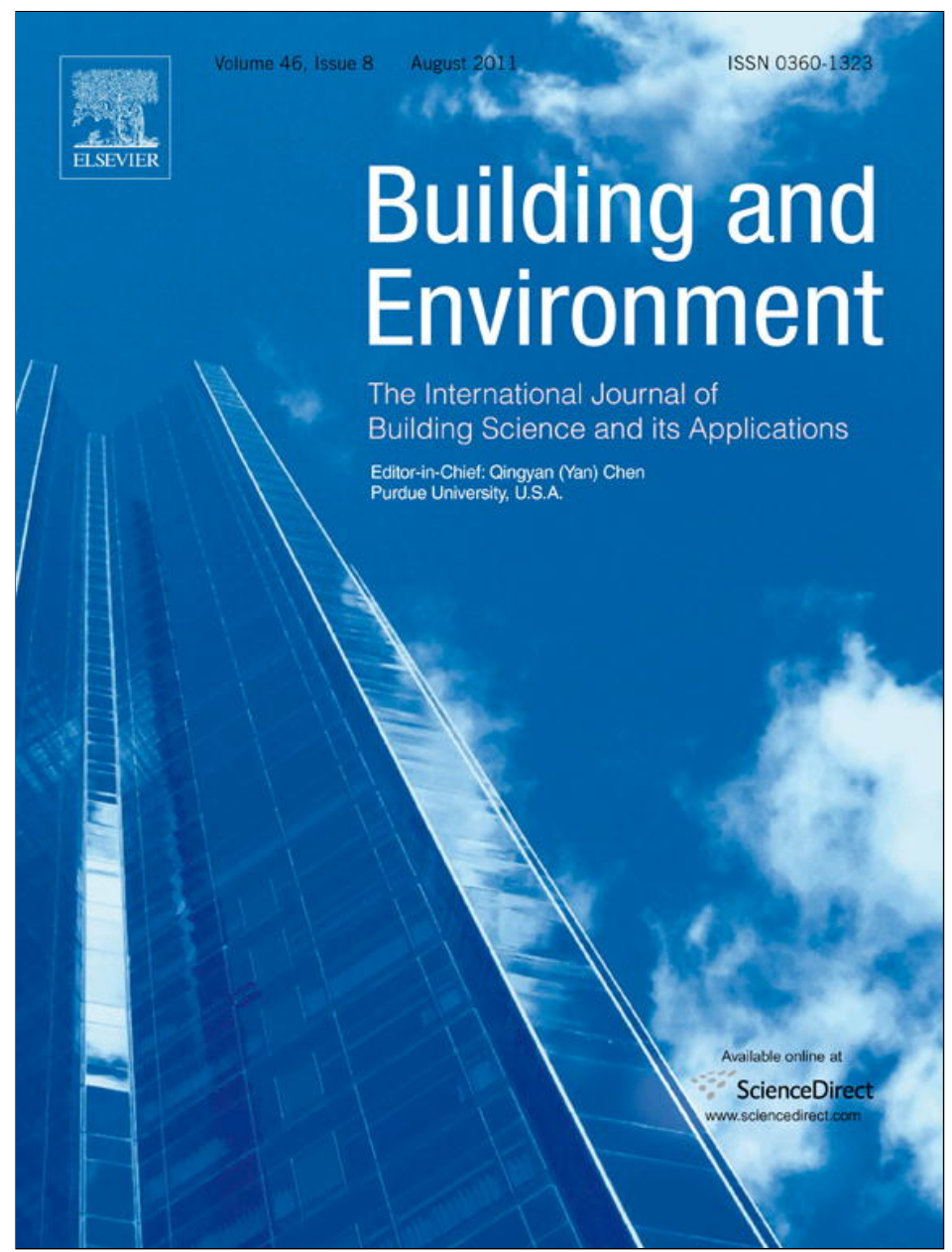

This article appeared in a journal published by Elsevier. The attached copy is furnished to the author for internal non-commercial research and education use, including for instruction at the authors institution and sharing with colleagues.

Other uses, including reproduction and distribution, or selling or licensing copies, or posting to personal, institutional or third party websites are prohibited.

In most cases authors are permitted to post their version of the article (e.g. in Word or Tex form) to their personal website or institutional repository. Authors requiring further information regarding Elsevier's archiving and manuscript policies are encouraged to visit:

http://www.elsevier.com/copyright 


\title{
Transient buoyancy-driven ventilation: Part 1. Modelling advection
}

\author{
Steven D. Sandbach*, Gregory F. Lane-Serff \\ School of Mechanical, Aerospace and Civil Engineering, University of Manchester, Pariser Building, Sackville Street, Manchester M13 9PL, UK
}

\section{A R T I C L E I N F O}

\section{Article history:}

Received 4 October 2010

Received in revised form

13 January 2011

Accepted 18 January 2011

\section{Keywords:}

Buoyancy

Ventilation

Doorway

Displacement

Natural

Modelling

\begin{abstract}
A B S T R A C T
The unsteady development of the vertical temperature profile in a ventilated space containing a heat source is modelled. The buoyant fluid released from the heat source is modelled as a turbulent buoyant plume, using a standard integral plume model with a fixed entrainment coefficient. Two types of natural ventilation flow are considered, with the flow driven entirely by the density contrast between the fluid inside and outside the space (stack effect). The ventilation types are (a) classic displacement ventilation, with outflow of warm air through upper openings and inflow of cool air through lower openings; and (b) doorway ventilation, with an exchange flow through the doorway. An improved version of the doorway exchange flow model is given as compared to previous studies. The boundaries of the space are considered to be perfectly insulating, so that heat is transported entirely by the fluid motion. The temporal stratification that develops within the space (outside the plume) is calculated using a modified filling-box model, with successive layers added to the top of the space over time. Laboratory experiments giving reduced-scale simulations of the flows were also conducted, where saline solution and fresh water are used to model fluid of different density. The developing density profiles in the laboratory experiments compare very well with the model predictions. The use of this type of model, capturing the main physical flow features, allows rapid and accurate calculations of transient stratification in ventilated spaces.
\end{abstract}

(c) 2011 Elsevier Ltd. All rights reserved.

\section{Introduction}

Inhabited spaces generally contain heat sources, derived for example from the occupants, electronic equipment (computers, printers, televisions, etc) or heating systems (radiators, fires, etc). To maintain thermal comfort and remove contaminants, these areas are normally provided with some form of ventilation. This ventilation may be driven by mechanical means, by natural pressure differences (wind/temperature) or by some combination of natural and mechanical forcing. In spaces containing heat sources, the resulting buoyancy within the room can be used to drive the flow, and we concentrate on these naturally driven flows in this paper.

The magnitude of the buoyancy forces scales with the density differences, and accelerations scale with the so-called reduced gravity $\left(g^{\prime}=\Delta \rho g / \rho\right.$, where $\Delta \rho$ is the density difference and $\rho$ a typical fluid density). We use this approach here, with the density of the ambient external air taken as our reference density. For typical temperatures in buildings, the density differences, and thus reduced gravity, are proportional to temperature differences, so the

\footnotetext{
* Corresponding author. College of Life and Environmental Sciences, University of Exeter, Amory Building, Rennes Drive, Exeter EX4 4RJ, UK

E-mail address: s.sandbach@exeter.ac.uk (S.D. Sandbach).
}

reduced gravity is a measure of the temperature relative to the external ambient temperature.

The resulting ventilation flows may be divided into two broad types: mixing flows and displacement flows. In mixing flows, the incoming fresh air is mixed throughout the space, producing a uniform distribution of thermal energy and contamination within the space. In displacement flows, cool air is introduced at a low level and exhaust air extracted at a high level. Here we concentrate on two types of displacement flow in a space containing a single heat source. The first is the "classic" displacement-ventilation flow described by Linden et al. [1], with openings near the top of the space to allow warm air to exit and openings near the bottom to allow cooler air to enter the space. The second is a space ventilated by an open doorway [2,3], where there is inflow of cooler air through the lower part of the doorway and outflow of warm air through the upper part of the doorway.

Methods for evaluating ventilation strategies include experimental and numerical modelling. In most cases, full-scale experimental representation of these flows is not practical, and scaling considerations $[1,4]$ make it difficult to conduct reduced-scale experiments (for thermally driven ventilation). Salt water bath experiments overcome some of these issues, where saline solution and fresh water is used to model density contrast [1,5]. This type of 


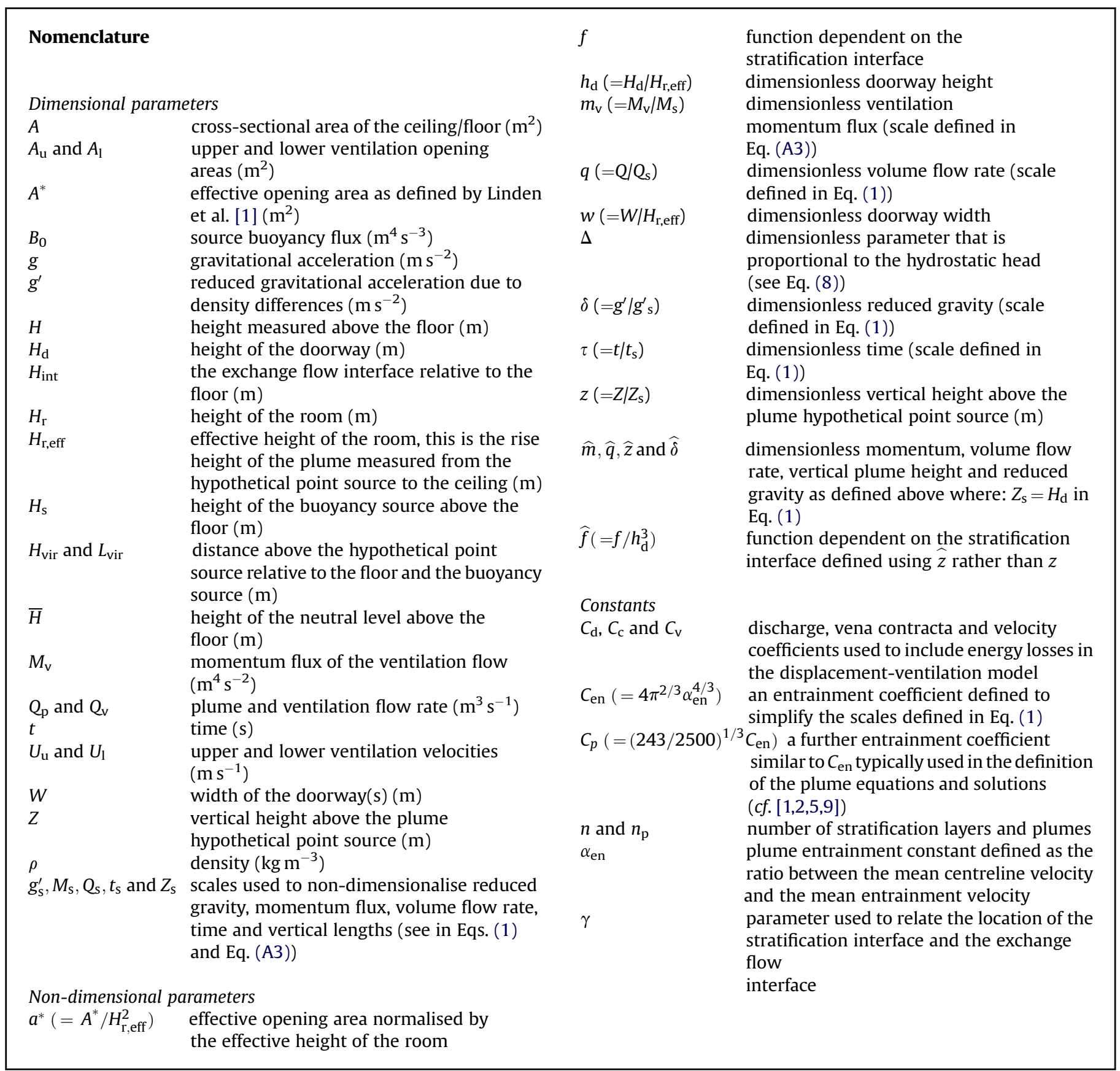

experiment captures the details of the flow, but does not simulate any heat transfers at the boundaries of the space.

Numerical models range from those based on simplified or averaged plume equations, referred to in this paper as mathematical models, to more complicated simulations using computational fluid dynamics (CFD). Using CFD, detailed flow patterns and temperature variations can be resolved and in principle these models include many of the important physical processes. However, in practice a degree of simplification is required and computational demands mean that these calculations are very time consuming. Simplified mathematical models offer an advantage of reduced time scale to calculate the solution as compared to CFD models, at the expense of physical complexity. For this reason, mathematical models are more useful in the early stages of design, as different ventilation strategies and configurations can be evaluated rapidly, with a more detailed CFD analysis later. In addition mathematical models help to identify functional dependencies that are not immediately clear from numerical experiments.

Mathematical models range in complexity. The main differences relate to the assumed temperature profile and the amount of physical processes modelled. There are three basic assumed temperature profiles: $i$ ) fully mixed [6-8]; $i$ i) fully mixed two-layer $[1,5,9]$; and iii) linear $[9,10]$. The two-layer and linear models are primarily based on experimental investigations. Some of these models include the effect of heat transfer at the boundaries, including radiative redistribution [9-11] and conductive heat transfer $[10,11]$, and they generally model only the steady-state flows.

In this paper, a new mathematical model for unsteady buoyancy-driven ventilation is proposed, giving the full detailed transient vertical stratification within the space. The model was developed and validated using experimental results obtained from 
reduced-scale salt water bath experiments. These experiments are described in the next section, with the proposed model detailed in Section 3. Results obtained using the new mathematical model are then compared with experimental results in Section 4 before some conclusions are drawn in Section 5. In an accompanying paper [12] we extend the model to include the effects of conductive and radiative heat transfers at the boundaries, and compare the model with full-scale experiments.

\section{Experiments}

In buoyancy-driven ventilation flows, temperature differences give rise to the density differences that drive the ventilation flow. In salt bath experiments, these density differences are modelled using saline solution and fresh water. The fresh water represents the ambient fluid and the saline solution represents the warm buoyant fluid, often dyed to aid visualisation. However, since saline solution is heavier than fresh water, the experiment needs to be inverted.

In this paper we present results obtained from a series of these experiments. A large tank with transparent sides measuring $1.50 \mathrm{~m} \times 1.00 \mathrm{~m} \times 0.47 \mathrm{~m}$ was filled with fresh water. A model room measuring $480 \mathrm{~mm} \times 355 \mathrm{~mm} \times 195 \mathrm{~mm}$ was suspended in the larger tank so that it was completely filled with fresh water. The model was inverted so that the floor was closer to the water surface than the ceiling. The model room was equipped with two doorways (measuring $135 \mathrm{~mm}$ by $53 \mathrm{~mm}$ each) and various ventilation openings in the floor and ceiling (see Table 1) to simulate both doorway and displacement-ventilation flows. This is a $1 / 15$ th scale model of the test room used in the accompanying paper [12]

In these experiments, the saline solution was introduced at the floor level to model the convective flow produced by a localised heat source. The saline solution was gravity fed to the model from a ten litre container providing a constant source volume flow rate of approximately $5.5 \mathrm{~cm}^{3} \mathrm{~s}^{-1}$. This was delivered to the model via a nozzle specifically designed to promote turbulence [13]. In each experiment, the source of saline solution was dyed and of constant density producing a constant buoyancy flux $\left(\sim 143-584 \mathrm{~cm}^{4} \mathrm{~s}^{-3}\right)$. The ensuing flow is a turbulent buoyant plume which is dynamically similar to the plume flow above a localised heat source.

Video footage of the ensuing flow was captured as a sequence of images using a progressive scan Pulnix digital camera (TM-1040) and analysed with flow visualisation software (Digiflow; developed by Dr Stuart Dalziel at the University of Cambridge). The camera has a one-megapixel square CCD (Charge-Coupled Device) capable of capturing 30 frames per second and was linked to a dual-core Pentium PC via a Roadrunner capture card. For each experimental configuration, the video recording commenced before the source was switched on to record background images for correction. Inversion of the images was required, as buoyancy was modelled using saline solution (heavier than fresh water). The flow was illuminated with a diffusive background and the progression of the flow was tracked visually. Digiflow was used to calculate the change in light intensity (due to absorption by the dye) from a mean background image at various times in the experiment using a logarithmic function [14].

Table 1

A summary of the experimental configurations.

\begin{tabular}{llll}
\hline \multicolumn{2}{l}{ Displacement ventilation } & & Number of open doorways \\
\hline$A_{\mathrm{u}}\left(\mathrm{cm}^{2}\right)$ & $A_{\mathrm{l}}\left(\mathrm{cm}^{2}\right)$ & $a^{*}$ & \\
\hline 2.8 & 9.6 & 0.004 & - \\
9.6 & 9.6 & 0.011 & - \\
- & - & - & 1 \\
- & - & - & 2 \\
\hline
\end{tabular}

The change in light intensity observed due to the presence of the dye was then used to infer the dye concentration. During each experiment, $5 \mathrm{ml}$ samples were taken within the buoyant layer at regular intervals to calibrate the images. The change in light intensity in the region close to where the samples were obtained was then used to obtain a relationship between the change in light intensity and buoyancy using a quadratic least-squares fit.

These results were used both to validate and to develop a mathematical model for these types of flows. In the following section, this model will be described with the results obtained from both the mathematical model and the experiments presented in Section 4.

\section{Mathematical modelling}

The turbulent buoyant plume rising from a heat source in a room can be modelled in terms of its mean properties, and this approach has been used successfully in a range of applications $[1,2,5,9,11,13,15,16,17]$. For plumes in enclosed spaces, it is convenient to non-dimensionlise these equations. For a filling-box flow, Worster and Huppert [15] defined dimensional scales for vertical length $Z_{\mathrm{s}}$, time $t_{\mathrm{s}}$, reduced gravity $g_{\mathrm{s}}^{\prime}$ and volume flow rate $Q_{\mathrm{s}}$. These were then used to define non-dimensional variables for height $z$, time $\tau$, reduced gravity $\delta$ and volume flow rate $q$ :

$$
\begin{aligned}
& z=Z_{\mathrm{s}}^{-1} Z=H_{\mathrm{r}, \mathrm{eff}}^{-1} Z, \\
& \tau=t_{\mathrm{s}}^{-1} t=C_{\mathrm{en}} H_{\mathrm{r}, \mathrm{eff}}^{2 / 3} A^{-1} B_{0}^{1 / 3} t, \\
& \delta=g_{\mathrm{s}}^{\prime-1} g^{\prime}=C_{\mathrm{en}} H_{\mathrm{r}, \mathrm{eff}}^{5 / 3} B_{0}^{-2 / 3} g^{\prime}, \\
& q=Q_{\mathrm{s}}^{-1} Q=C_{\mathrm{en}}^{-1} H_{\mathrm{r}, \mathrm{eff}}^{-5 / 3} B_{0}^{-1 / 3} Q,
\end{aligned}
$$

where $H_{\mathrm{r}, \text { eff }}$ is the effective room height (see Fig. 1), $A$ is the area of the floor, $B_{0}$ is the source buoyancy flux and $C_{\mathrm{en}}\left(=4 \pi^{2 / 3} \alpha_{\mathrm{en}}^{4 / 3}\right)$ is dependent on the entrainment coefficient $\alpha_{\text {en }}$, defined as the ratio between the entrainment and plume centreline velocities [5]. We assume here that the horizontal dimensions of the room are sufficiently large compared to the height, so that the plume is not affected by the sidewalls. In this case, the entrainment coefficient is constant and here we take $\alpha_{\mathrm{en}}=0.085$, so $C_{\mathrm{en}}=0.321$.

This set of parameters is obtained from dimensional analysis of the turbulent plume equations. The vertical length scale $Z_{\mathrm{s}}$ is defined as the rise height of the plume (see Fig. 1). This is relative to a hypothetical 'virtual' point that defines the plume origin: $Z=0$. For 'real' sources of buoyancy, a virtual length scale $\left(L_{\mathrm{vir}}\right.$ here, see Fig. 1) should be included and this virtual length scale depends on

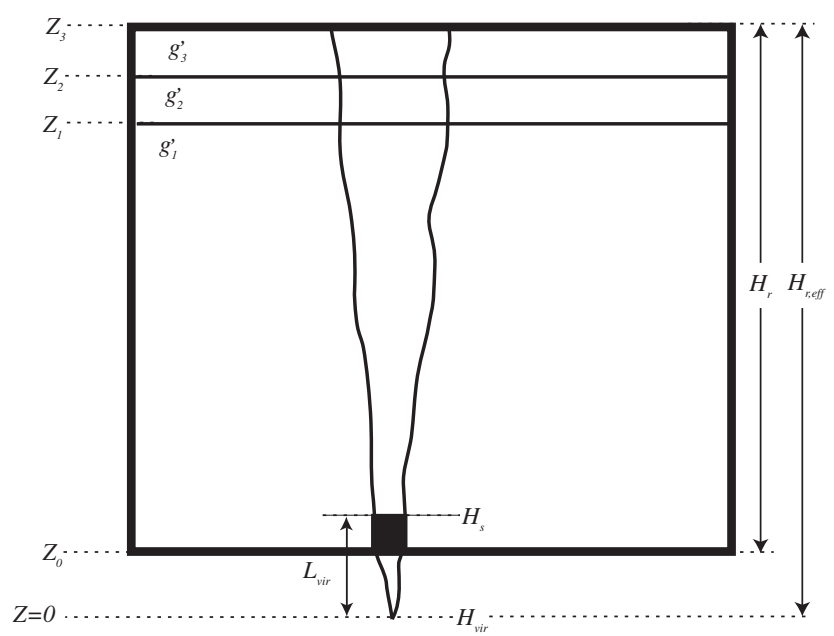

Fig. 1. Schematic representation of the filling-box model at $t=2 \Delta t$. 
the source conditions [18-20]. However, for ventilation flows the floor is a convenient datum and since the virtual origin of the plume and the floor level do not necessarily coincide, it is helpful to use a linear transformation of the form: $H=Z+H_{\text {vir }}$. Here $H_{\text {vir }}$ $\left(=L_{\mathrm{vir}}+H_{\mathrm{s}}\right)$ is the location of the virtual origin and $H_{\mathrm{s}}$ is the location of the buoyancy source with respect to the floor (see Fig. 1).

\subsection{Filling-box model}

A schematic representation of the filling-box model proposed by Germeles [16] is presented in Fig. 1. At the start of the simulation, it is assumed that the density of the fluid in the room is uniform and that the plume has just reached the ceiling. During each time step, a layer of buoyant fluid is added, with the density calculated from the volume and buoyancy flux in the plume(s). This is calculated using the turbulent plume equations and solutions [21].

For the plume flow between the buoyant source and the first interface $\left(z_{1}\right)$, the plume solutions are valid and so the volume, buoyancy and momentum flux in the plume can be computed analytically. However, above this interface, it is necessary to integrate these equations numerically (see Germeles [16] for further details).

To calculate the change in depth and the advection of each layer within the room, Germeles [16] obtained a relationship between the plume volume flow rate $\left(q_{\mathrm{p}, i}\right)$, interface location $\left(z_{i}\right)$ and time step $(\Delta \tau)$. This was obtained from a consideration of mass conservation, where the cross-sectional area of the room was assumed to be much larger than the cross-sectional area of the plume. In this paper we present a modified version of this to include the influence of the ventilation flow $\left(q_{\mathrm{v}}\right)$ and to include multiple $\left(n_{\mathrm{p}}\right)$ equalstrength sources:

$z_{i}^{\text {new }}=z_{i}^{\text {old }}+\left(q_{\mathrm{v}}-n_{\mathrm{p}} q_{\mathrm{p}, i}\right) \Delta \tau$,

where $q_{v}$ is the non-dimensional ventilation flow rate, equal to zero for filling-box flows. For buoyancy-driven ventilation, the ventilation flow is dependent on the configuration. Here, we consider both displacement ventilation and doorway ventilation and in the following two sections outline how $q_{\mathrm{v}}$ is calculated in each case.

\subsection{Displacement ventilation}

To model displacement ventilation, an approach similar to that of Linden et al. [1] was adopted. The ventilation flow rate was calculated using a combination of the Bernoulli equation, the hydrostatic head equation and mass conservation. In Fig. 2a, a schematic representation of the model is presented. In this case, the hydrostatic head produced by the cooler air outside the room is greater than the hydrostatic head produced by the warmer air inside the room at the lower opening. The opposite is true at the upper opening, and so there is an inflow through the lower opening (s) and an outflow through the upper opening(s).

At some vertical location between the lower and upper openings the pressure difference between the air inside and outside the room is zero. This is often referred to as the neutral level, here denoted by $\bar{H}$, and is arbitrarily assumed to occur within the second layer in Fig. 2a. Matching the hydrostatic head above and below the neutral level to the pressure difference at the upper and lower openings respectively using Bernoulli's equation we obtain:

$\frac{U_{\mathrm{u}}^{2}}{2 C_{\mathrm{v}, \mathrm{u}}}=g_{3}^{\prime}\left(H_{3}-H_{2}\right)+g_{2}^{\prime}\left(H_{2}-\bar{H}\right)$,
$\frac{U_{1}^{2}}{2 C_{\mathrm{v}, \mathrm{l}}}=g_{1}^{\prime}\left(H_{1}-H_{0}\right)+g_{2}^{\prime}\left(\bar{H}-H_{1}\right)$,

where $U_{\mathrm{u}}, U_{\mathrm{l}}, C_{\mathrm{v}, \mathrm{u}}$ and $C_{\mathrm{v}, \mathrm{l}}$ are the respective velocity and velocity coefficient for the upper and lower openings, $g_{i}^{\prime}\left(=g\left(\rho_{0}-\rho_{i}\right) \rho_{0}^{-1}\right)$ is the reduced gravity of the $i$ th layer (see Fig. $2 \mathrm{a}$ ) and $\rho_{\mathrm{o}}$ is the density of the fluid outside the space. The velocity coefficient is introduced to account for energy losses through the opening. Eliminating $\bar{H}$ in Eqs. (3) and matching the volume flow rate through the upper and lower openings using the continuity principle, we obtain:

$\left[\frac{1}{C_{\mathrm{v}, \mathrm{l}}}+\frac{1}{C_{\mathrm{v}, \mathrm{u}}}\left(\frac{A_{\mathrm{l}} C_{\mathrm{c}, \mathrm{l}}}{A_{\mathrm{u}} C_{\mathrm{c}, \mathrm{u}}}\right)^{2}\right] \frac{U_{\mathrm{l}}^{2}}{2}=\sum_{i=1}^{n} g_{i}^{\prime}\left(H_{i}-H_{i-1}\right)$,

where $C_{c}$ is the contraction coefficient (vena contracta, see [23]), $H_{n}=H_{\mathrm{r}}$ and $H_{0}=0$ (see Fig. 2a). Setting $H=Z+H_{\text {vir }}$, it is possible to write Eq. (4) in terms of the ventilation flow rate $Q_{v}\left(=U_{l} A_{1} C_{c, 1}\right)$ :

$Q_{\mathrm{v}}=A^{*}\left(\sum_{i=1}^{n} g_{i}^{\prime}\left(Z_{i}-Z_{i-1}\right)\right)^{1 / 2}$,

where

$A^{*}=\frac{\sqrt{2} A_{\mathrm{u}} A_{\mathrm{l}}}{\sqrt{A_{\mathrm{u}}^{2} / C_{\mathrm{d}, \mathrm{l}}^{2}+A_{\mathrm{l}}^{2} / C_{\mathrm{d}, \mathrm{u}}^{2}}}$

is the effective opening area and $C_{\mathrm{d}}\left(=C_{\mathrm{C}} C_{\mathrm{V}}\right)$ is the discharge coefficient. It has been shown that the discharge coefficient is a

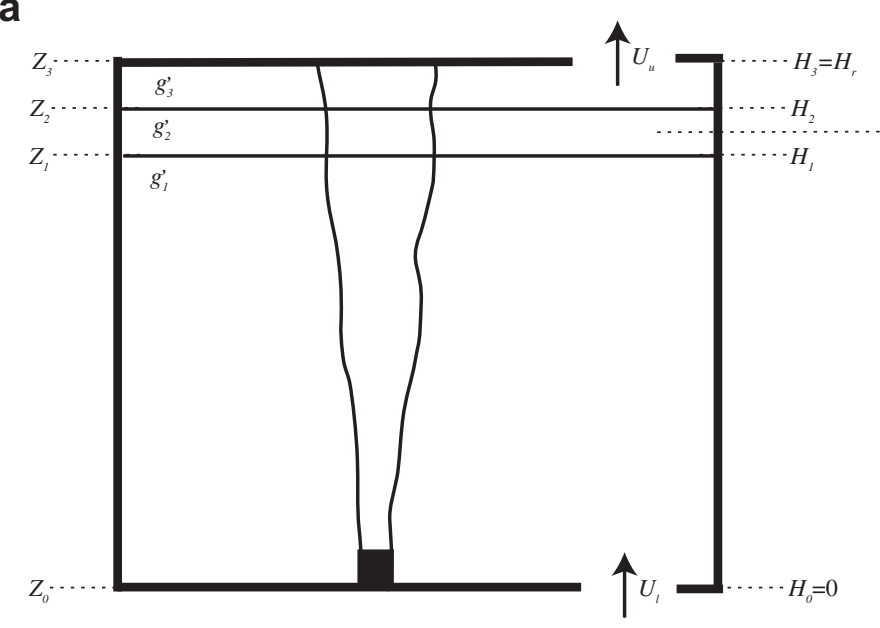

b

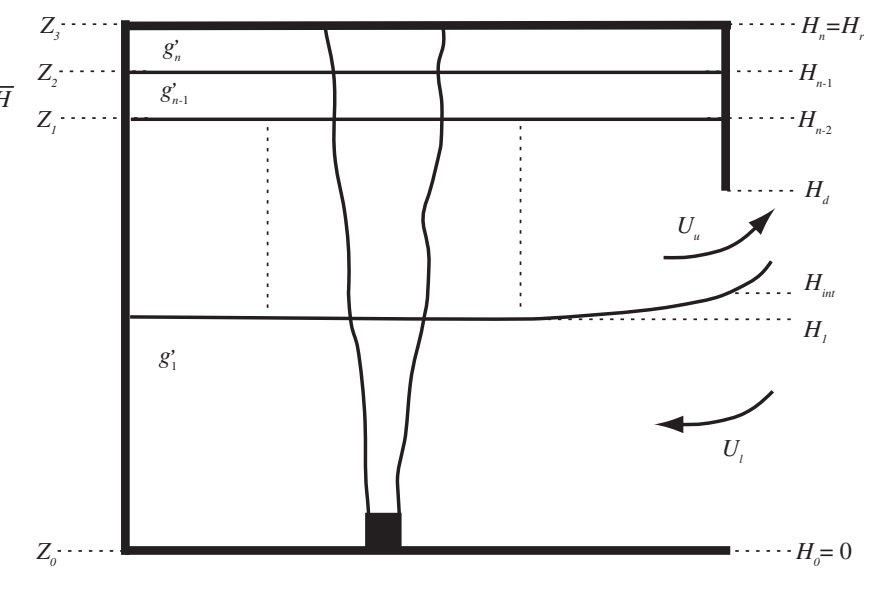

Fig. 2. Schematic representation of the ventilation model. (a) Displacement-ventilation model and (b) doorway model. 
dependent on the Reynolds number $[22,23]$ and the temperature difference across the ventilation opening $[24,25]$. However, for the flows considered here, these effects are not significant [26] and we therefore apply a constant value $\left(C_{d}=0.61\right.$ unless otherwise stated).

Using the scales defined in Eqs. (1), Eq. (5) can be nondimensionalised:

$q_{\mathrm{v}}=C_{\mathrm{en}}^{-3 / 2} a^{*} \Delta^{1 / 2}$,

where

$a^{*}=\frac{A^{*}}{H_{\mathrm{r}, \mathrm{eff}}^{2}}$,

$\Delta=\sum_{i=1}^{n} \delta_{i}\left(z_{i}-z_{i-1}\right)$.

The parameter $a^{*}$ is a dimensionless effective opening area and $\Delta$ is proportional to the hydrostatic head produced by the buoyant fluid.

\subsection{Doorway ventilation}

In this case, an exchange flow is set up; this was modelled following an approach similar to that of Phillips and Woods [2]. The flow through the doorway is hydraulically controlled, so the composite Froude number is unity there (see $[3,27]$ for details of hydraulic control and doorways):

$\frac{U_{\mathrm{u}}^{2}}{H_{\mathrm{d}}-H_{\mathrm{int}}}+\frac{U_{\mathrm{l}}^{2}}{H_{\mathrm{int}}}=\bar{g}^{\prime}$,

where $H_{\mathrm{d}}$ and $H_{\text {int }}$ are the height from the floor to the top of the doorway and the exchange interface respectively (see Fig. 2b) and $\bar{g}^{\prime}$ is the average reduced gravity of the layers above the stratification interface. For a room containing multiple doorways of equal height, the effective doorway width $(W)$ can be calculated by summing the widths of the individual doorways, and from mass conservation we may write:

$Q_{\mathrm{v}}=U_{\mathrm{u}} W\left(H_{\mathrm{d}}-H_{\mathrm{int}}\right)=U_{\mathrm{l}} W\left(H_{\mathrm{int}}-H_{0}\right)$.

Combining Eqs. (9) and (10) to eliminate the velocity terms, nondimensionalising using the scales in Eqs. (1) and setting $H=Z+H_{\text {vir }}$, the ventilation flow rate can be obtained:

$q_{\mathrm{v}}=w C_{\mathrm{en}}^{-3 / 2} f^{1 / 2} \bar{\delta}^{1 / 2}$,

where $\bar{\delta}\left(=\Delta\left(1-z_{1}\right)^{-1}\right)$ is the average non-dimensional reduced gravity of the upper layers, $w\left(=W / H_{\mathrm{r} \text {,eff }}\right)$ is the normalised doorway width and $f$ is a non-dimensional function dependent on the room geometry and exchange interface height:

$f\left(z_{\text {int }}\right)=\frac{\left(z_{\mathrm{d}}-z_{\text {int }}\right)^{3}\left(z_{\text {int }}-z_{0}\right)^{3}}{\left(z_{\mathrm{d}}-z_{\text {int }}\right)^{3}+\left(z_{\text {int }}-z_{0}\right)^{3}}$.

In an experimental investigation, Phillips and Woods [2] found that the location of the interface between the fluid exchanged through the doorway $\left(z_{\text {int }}\right)$ and the stratification interface $\left(z_{1}\right)$ in the room (see Fig. 2b) can be approximated in two parts. When the exchange interface is below 55\% of the doorway height, the flow is controlled by the doorway, a result also found by Dalziel and LaneSerff [3]. In this case, the doorway interface remains at 55\% of the doorway height (see Eqs. (14)). Above this height, they found that the stratification interface in the room and the interface at the doorway were at approximately the same level $\left(z_{\mathrm{int}} \approx z_{1}\right)$. Phillips and Woods [2] then use these approximations to write the function $f$ in terms of $z_{1}$ (see Eq. (12)).

However, here we propose a new relationship between the exchange interface and stratification interface. This is obtained by tracing the flow along the stratification interface in the room to the doorway using the Bernoulli equation (and assuming negligible flow speed in the room), giving the classic result for flow from a large reservoir over a weir so that:

$\left(z_{\mathrm{d}}-z_{\text {int }}\right)=2 / 3\left(z_{\mathrm{d}}-z_{1}\right)$.

Modified in this way, the interface at the doorway is calculated as follows:

$z_{\text {int }} \approx(1-\gamma) z_{\mathrm{d}}+\gamma z_{1} \quad$ for $z_{\mathrm{d}}>z_{\text {int }}>0.55 z_{\mathrm{d}}+0.45 z_{0}$,

$z_{\text {int }}=0.55 z_{\mathrm{d}}+0.45 z_{0}$ for $z_{\text {int }} \leq 0.55 z_{\mathrm{d}}+0.45 z_{0}$,

where $\gamma=2 / 3$ in the new and $\gamma=1$ in the original [2] approximations; in this paper we use the new approximation $(\gamma=2 / 3)$ unless otherwise stated. During the initial filling, while the upper layer is above the doorway $\left(z_{1}>z_{\mathrm{d}}\right)$ there is no exchange flow and so $q_{\mathrm{v}}=0$. Once the flow reaches the top of the doorway, an exchange flow is set up and $q_{v}$ is calculated using Eqs. (11)-(14). We shall now compare the mathematical-model and experimental results.

\section{Results}

The results obtained in these reduced-scale experiments are very useful, as they permit simple yet effective means of investigating ventilation flows and have proved crucial in developing and validating models for buoyancy-driven ventilation [1-3,5]. Images collected from each experiment can be used both to visualise the flow and to provide validation data for simple mathematical models.

In this section we use experimental and mathematical-model results to investigate these ventilation flows. To start, we investigate the filling flow produced by a single buoyant source using a series of images. In this experiment, a single open doorway was used to ventilate the space. Following this, the experimental results are compared with the mathematical-model results. Finally, we use the model developed to investigate the transient behaviour of the flow for a wider range of geometrical parameters.

\subsection{Experimental observations}

In Fig. 3, a series of images that depict the filling of a room ventilated by a single open doorway are presented. The images are inverted, as in these experiments the buoyancy is introduced using dyed saline solution and fresh water. The non-dimensional time $\tau$ is given (calculated using the scales discussed, Eqs. (1)) and represents the time each image was obtained from the start of the experiment (when the plume initially reaches the ceiling).

In the early stages of the flow, the filling mechanism observed for an unventilated space (filling-box) is produced (Fig. 3a\&b). The flow in the plume that reaches the ceiling is forced to spread radially, forming a forced gravity-driven flow on the ceiling (Fig. 3a). This buoyant fluid starts to fill the room and the layer deepens, eventually reaching the top of the doorway (Fig. 3b). As the flow continues to fill the room, an exchange flow is set up and some of the buoyant fluid is ventilated out of the room through the doorway (see Fig. 3c). As the buoyant layer deepens, the ventilation flow rate increases (see Fig. 3d) until the mass and buoyancy flux in the plume matches the ventilated flow. As time increases, the inflow produces a circulatory flow within the lower layer that deflects some of the plume fluid, depositing it on the stratification interface. The plume moves in an approximately circular motion in 


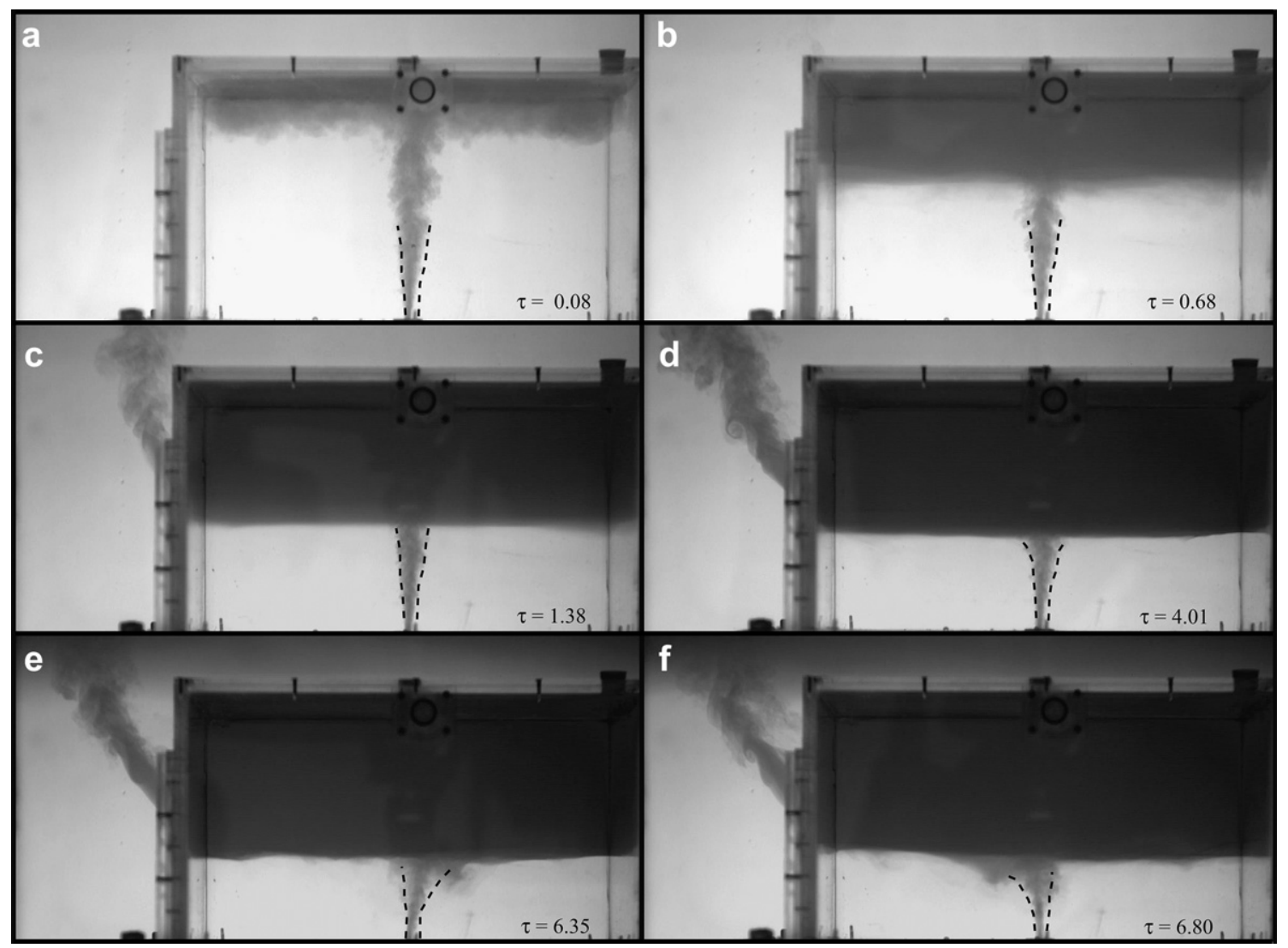

Fig. 3. The filling of a room containing a buoyant source $\left(B_{0}=344 \mathrm{~cm}^{4} \mathrm{~s}^{-1}\right.$ and $\left.Q_{0}=6.8 \mathrm{~cm}^{3} \mathrm{~s}^{-1}\right)$ ventilated by a single doorway. The time each frame was taken is given in nondimensional time $\tau$ where the filling-box time scale $t_{\mathrm{s}}=96 \mathrm{~s}$ (see Eqs. (1)). (a) The plume collides with the ceiling spreading laterally and forming a gravity current. (b) The fluid advected at the ceiling starts to fill the room with buoyant fluid. (c) The buoyant layer deepens and some of this fluid is exchanged through the doorway. (d) The buoyant layer continues to deepen as the ventilation flow rate increases and the flow approaches steady-state. (e) The flow ventilated in through the doorway produces a circulatory flow in the lower layer, deflecting the plume. (f) The plume moves in an approximately circulatory motion driven by the ventilation flow.

the horizontal plane and when viewed from the side appears to move periodically from side to side (see Fig. 3e\&f).

This circulatory pattern was not observed in the experiments where two doorways were used and there are two reasons to explain this. Firstly, the doorways were located on opposite ends of the same wall. In this case, any circulation set up by the flow through one of the doorways is damped by the flow through the other doorway. Secondly, the momentum of the ventilation flow is increased as the doorway aspect ratio increases (see Appendix). In the two-doorway case, the effective doorway width is double that of the single-doorway case, and so the momentum is reduced.

\subsection{Model comparisons}

We shall now compare the mathematical-model and the experimental results. As already discussed, it may be necessary to offset the results using the virtual origin length scale $\left(H_{\mathrm{vir}}\right)$. In these experiments, the source of buoyancy was located at the floor level $\left(H_{\mathrm{s}}=0 \mathrm{~cm}\right)$ and the virtual origin was calculated using the conical correction method (see Hunt and Kaye [19]). For a buoyancy flux of 160,314 and $588 \mathrm{~cm}^{4} \mathrm{~s}^{-3}$, this was evaluated to be $-4.6,-3.0$ and $-2.5 \mathrm{~cm}$ respectively.

In Fig. 4, the vertical buoyancy $(\delta)$ stratification in the experiments is compared with results obtained using the mathematical model. The results are presented at various times $(\tau=0.24,0.88$, 1.92 and 4.01) for displacement ventilation ( $\mathrm{a} \& \mathrm{~b})$ and for doorway ventilation $(c \& d)$.
For the displacement-ventilation flows, the model results are presented for two discharge coefficients $\left(C_{d}=1.0\right.$ and 0.61$)$. These results show that an increase in the discharge coefficient results in an increase in the stratification interface height and a reduction in the buoyancy of the fluid above the stratification interface. This is to be expected, as increasing the discharge coefficient effectively increases the ventilation flow rate (see Eq. (7)).

These results reveal an excellent agreement between the mathematical model and the experiments for (a) $a^{*}=0.004$, but very poor agreement for (b) $a^{*}=0.011$. For $a^{*}=0.011$, there are three distinct layers evident in the experimental results at later times; this is due to mixing between the upper and lower layers produced by the jet that is formed at the inlet. In an experimental study of draining displacement-ventilation flows, Coffey and Hunt [17] found that weak mixing was evident at the stratification interface, which became more vigorous as the area ratio $A_{\mathrm{u}} / A_{\mathrm{l}}$ approached one. This is consistent with the results obtained here, as the area ratio equals 0.3 and 1.0 for $a^{*}=0.004$ and $a^{*}=0.011$ respectively.

The results obtained for the doorway configurations appear to compare less well than the displacement-ventilation model (for $a^{*}=0.011$ ). Further to this, in some cases there is a discrepancy between the experimental results obtained (for different buoyancy source conditions) for both room configurations (see Fig. 4c\&d). In each case, there is good agreement between the experimental results for two of the source conditions. However, when comparing the third data set there is a discrepancy between the results obtained. 
a

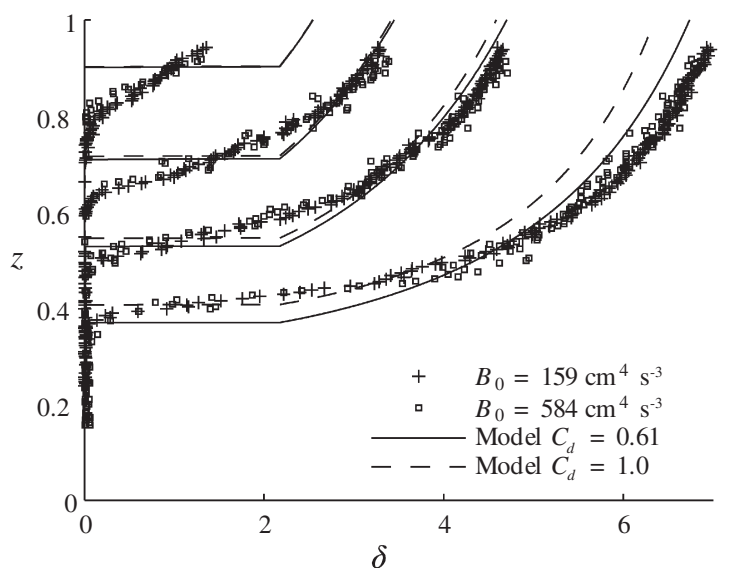

C

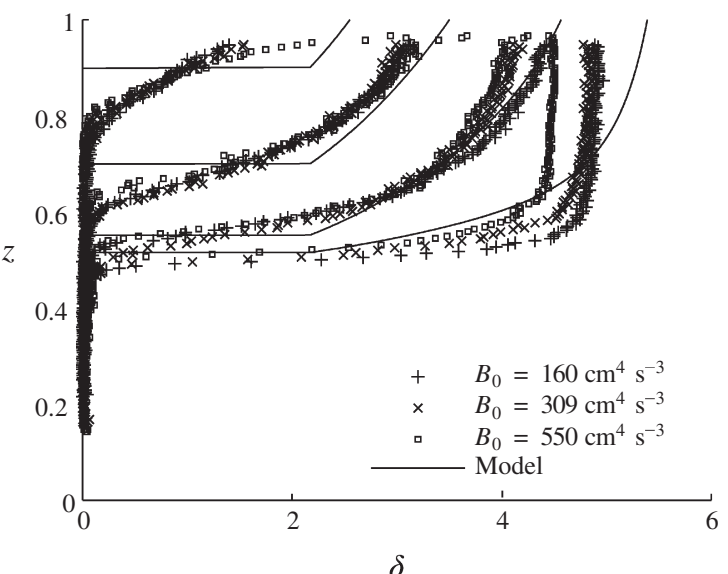

b

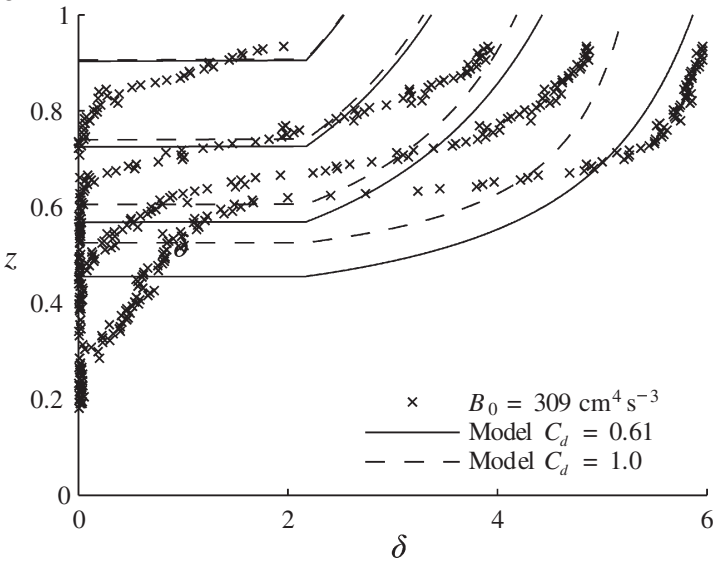

d

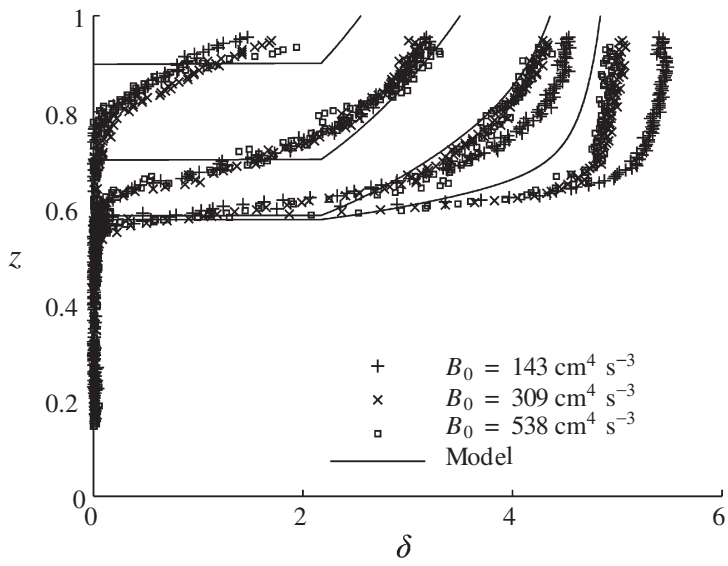

Fig. 4. Vertical buoyancy stratification for displacement ventilation (a\&b) and doorway ventilation (c\&d). (a) $a^{*}=0.004\left(C_{\mathrm{d}}=0.61\right)$; (b) $a^{*}=0.011\left(C_{\mathrm{d}}=0.61\right) ;(\mathrm{c})$ One open doorway; and (d) Two open doorways.

In the single-doorway case, the results obtained using a source buoyancy flux of $550 \mathrm{~cm}^{4} \mathrm{~s}^{-3}$ are lower in terms of non-dimensional buoyancy $(\delta)$ than those obtained for the other two source conditions $\left(B_{0}=309 \mathrm{~cm}^{4} \mathrm{~s}^{-3}\right.$ and $\left.160 \mathrm{~cm}^{4} \mathrm{~s}^{-3}\right)$. In the doubledoorway case, the results obtained using a source buoyancy flux of $143 \mathrm{~cm}^{4} \mathrm{~s}^{-3}$ are higher in terms of non-dimensional buoyancy $(\delta)$ than those obtained using the other two source conditions $\left(B_{0}=308\right.$ and $\left.538 \mathrm{~cm}^{4} \mathrm{~s}^{-3}\right)$. The origin of this error is not known; however, the error is small and there is a very good agreement between the experimental and the mathematical-model results.

In Fig. 5, the location of the stratification interface as a function of non-dimensional time $(\tau)$ is presented. These values were obtained by evaluating the point vertically where the density changed significantly. Both mathematical-model and experimental results are presented for: (a) $a^{*}=0.011$; (b) single doorway; and (c) double-doorway configurations. For the displacement-ventilation results (Fig. $5 \mathrm{a}$ ), the discharge coefficient $\left(C_{\mathrm{d}}\right)$ was set equal to 0.61 (broken line) and 1 (solid line) in computing the mathematicalmodel results. There is good agreement between the new mathematical model and the experimental results, with most of the data falling in the region bounding the two sets of model results $\left(C_{\mathrm{d}}=0.61\right.$ and 1.0$)$.

For the doorway configurations (Fig. 5b\&c), the mathematicalmodel results were computed setting $\gamma=2 / 3$ (the new approximation, solid line) and $\gamma=1$ (original approximation [2], broken line) in Eqs. (14). Using the new approximation, the buoyant layer penetrates deeper as compared to the existing approximation. This is to be expected, as the exchange interface height controls the ventilation flow rate (see Eq. (12)). Comparison between the mathematical-model and the experimental results shows that the new doorway flow approximation significantly improves tracking of the stratification interface.

The long-term behaviour for the single-doorway case (although better represented by the new approximation) is less well modelled than for the double-doorway case. This is because, in the singledoorway case, it is difficult to clearly measure the interface location, as some of the fluid in the plume is deflected onto the stratification interface (as described earlier and shown in Fig. 3).

\subsection{Effect of changing geometric parameters}

In the previous section we found that there was an excellent agreement between the new mathematical model and the experiments. In this section, we use this model to investigate the effect of changing geometrical parameters on the transient development of the flow. For both doorway and displacement-ventilation flows, the steady-state stratification interface height $\left(z_{\mathrm{ss}}\right)$ is independent of the source buoyancy flux and depends only on geometrical parameters [1,2]. In non-dimensional terms, the same is true for the transient filling flow, but it is worth noting that the time scale $t_{\mathrm{s}}$ 

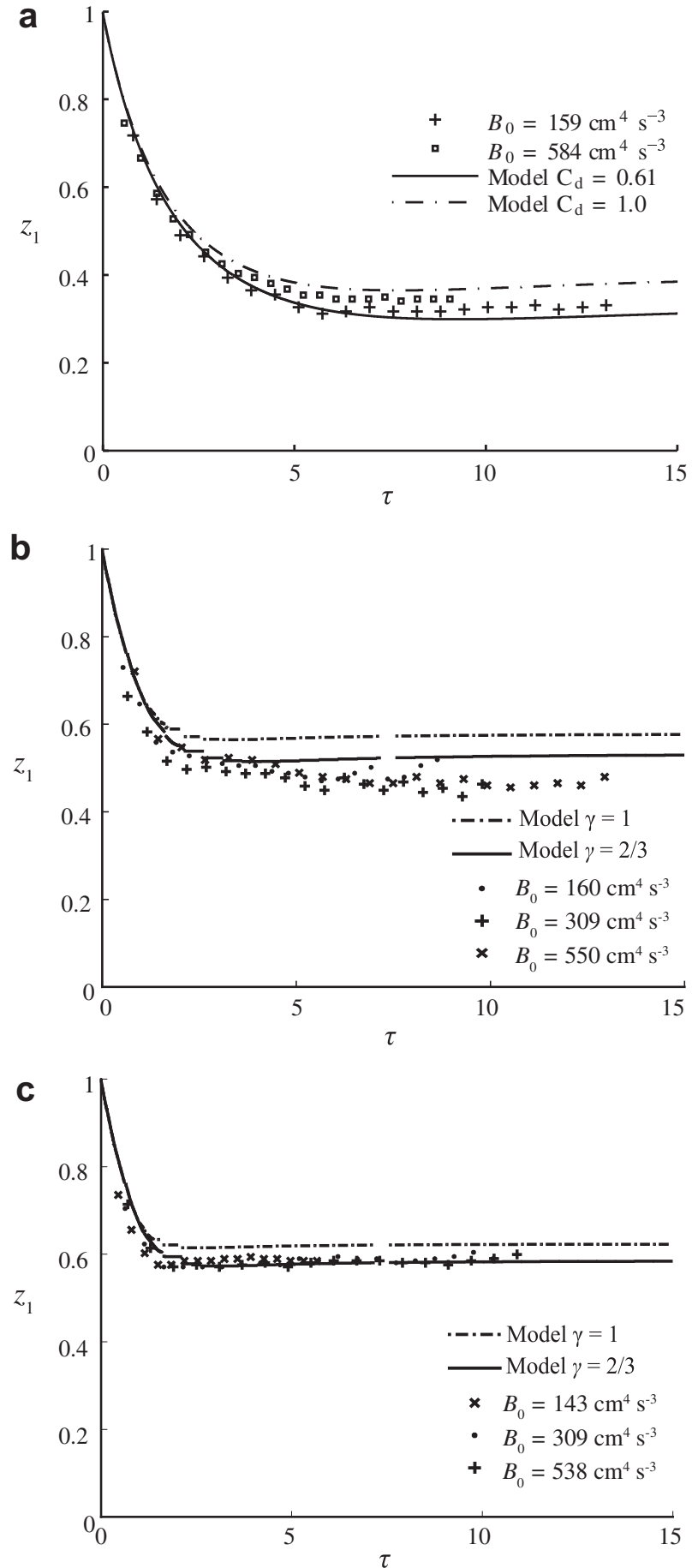

Fig. 5. Stratification interface height as a function of time for displacement ventilation (a\&b) and doorway ventilation (b\&c). (a) $a^{*}=0.004\left(C_{\mathrm{d}}=0.61\right)$; (b) One open doorway; and (c) Two open doorways.

(see Eqs. (1)) is dependent on the source buoyancy flux. This simply controls the actual length of time the flow requires to reach steadystate. For this reason, we investigate the influence of geometric parameters on the transient filling (for both doorway and displacement-ventilation flows).

\subsubsection{Displacement ventilation}

The transient filling of a space ventilated by displacement ventilation was investigated by Kaye and Hunt [5] using their

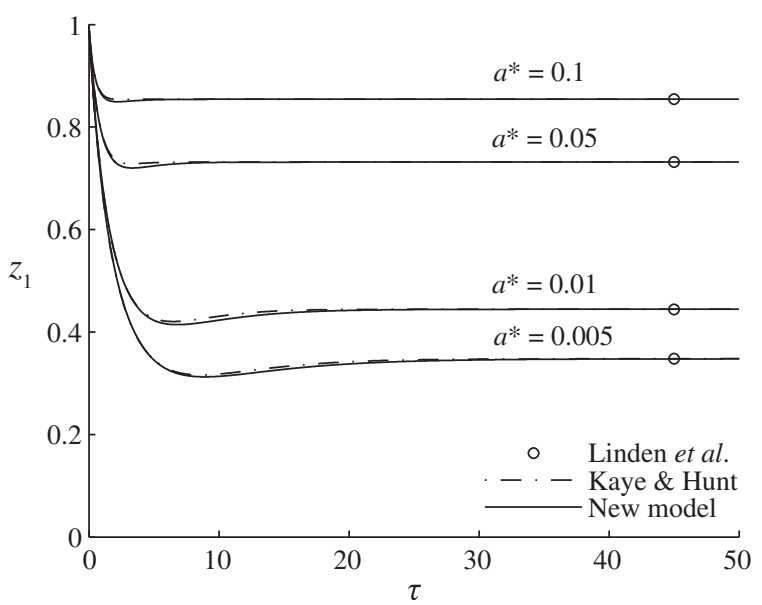

Fig. 6. Temporal evolution of the stratification interface in a space ventilated by displacement ventilation.

unsteady two-layer model. During the initial transient phase, the stratification interface descends and for $a^{*}<0.25 n_{\mathrm{p}} C_{\mathrm{p}}^{3 / 2}$, the interface overshoots the steady-state height $\left(z_{\mathrm{ss}}\right)$ before ascending back up towards the steady-state location predicted by Linden et al. [1]. The constant $C_{\mathrm{p}}$ is dependent on the entrainment coefficient $\alpha_{\mathrm{en}}$ and is related to the entrainment constant used in Eqs. (1): where $C_{\mathrm{p}}=(243 / 2500)^{1 / 3} C_{\mathrm{en}}$, so that the reduced gravity in the plume $g_{\mathrm{p}}^{\prime}=C_{\mathrm{p}}^{-1} B_{0}^{2 / 3} Z^{-5 / 3}$ (see [21]) and $C_{\mathrm{p}}=0.147$.

Results that characterise this filling flow are presented in Fig. 6 for $C_{\mathrm{d}} a^{*}=0.1,0.05,0.01$ and 0.005 . These results were obtained using the steady [1] (circles at $\tau=45$ ) and unsteady [5] (broken line) two-layer models and the new unsteady stratified model (solid line).

These results show that both the new stratified model and the unsteady two-layer model [5] predict similar transient development of the flow. They also show that the new model predicts deeper penetration, as the interface height overshoots the final steady location. Further to this, the model time scale required for the flow to reach steady-state is also increased. These differences are related to the way in which the buoyancy of the fluid above the stratification interface is modelled. Kaye and Hunt [5] assume the upper layer to be well mixed (uniform buoyancy), whereas this is modelled as a series of layers of different buoyancy in our new model. For this reason, the buoyancy is more spread out (as compared to the two-layer model [5]) and so the buoyant layer penetrates further into the room.

\subsubsection{Doorway ventilation}

For doorway flows, there are two key parameters that control the filling process: $i)$ the doorway aspect ratio $R\left(=H_{\mathrm{d}} / W\right)$ which controls the final location of the stratification interface [2] (see Eq. (15)); and ii) the relative height of the doorway $h_{\mathrm{d}}\left(=H_{\mathrm{d}} / H_{\mathrm{r}, \text { eff }}\right)$ which, as we shall see, controls the depth that the upper layers overshoot the steady-state height and the filling time scale required to reach steady-state.

For doorway flows, it is possible to show that the steady-state stratification interface height $\left(z_{\mathrm{ss}}\right)$ is independent of the source buoyancy flux [2] with the interface height related to the aspect ratio by:

$R=C_{\mathrm{p}}^{-3 / 2} \widehat{z}_{\mathrm{ss}}^{-5 / 2} \widehat{f}_{\mathrm{ss}}^{1 / 2}$

where $\widehat{f}_{\text {ss }}$ is the function (Eq. (12)) evaluated by setting $\widehat{z}_{1}=\widehat{z}_{\text {ss }}$ in Eqs. (14) and $\widehat{z}\left(=h_{\mathrm{d}}^{-1} z\right)$ is the non-dimensional vertical height from 
the plume source scaled to the height of the doorway rather than the effective room height. Assuming the virtual origin and the entrainment coefficient remain constant, the steady-state location of the stratification interface depends only on the doorway aspect ratio [2].

As the steady-state flow scales on the doorway height, it is convenient for comparative purposes to rescale the flow parameters using this length scale:

$\widehat{q}=h_{\mathrm{d}}^{-5 / 3} q$,

$\widehat{\delta}=h_{\mathrm{d}}^{5 / 3} \bar{\delta}$,

where $\widehat{q}$ and $\widehat{\delta}$ are the non-dimensional volume flow rate and reduced gravity obtained by replacing $H_{\mathrm{r} \text {,eff }}$ with $H_{\mathrm{d}}$ in Eqs. (1). In this theoretical analysis, we are interested in the flow development once the stratification interface reaches the top of the doorway. For flows where $h_{\mathrm{d}}<1$, there is an initial transient where the flow fills the space above the doorway. The non-dimensional time scale of this filling process can be computed using the plume solutions in a filling-box (see Worster and Huppert [15]) and is dependent on the relative height of the doorway $h_{\mathrm{d}}$ :

$\tau_{\mathrm{s}}=5\left(\frac{5}{18}\right)^{1 / 3}\left(h_{\mathrm{d}}^{-2 / 3}-1\right)$.

This initial transient is not of interest here and so the results presented are offset using this time scale $\left(\widehat{\tau}=\tau-\tau_{\mathrm{s}}\right)$. It is also convenient in this theoretical analysis to assume that the virtual origin is located at the floor level $\left(\widehat{z}_{0}=0\right)$.

In Fig. 7a, a plot of the stratification interface height as a function of non-dimensional time is presented for various aspect ratios: $R=1,2,4$ and 10 . The results are given for $h_{\mathrm{d}}=1$ and 0.5 and this is equivalent to a doorway of equal room height and half room height respectively. For each configuration, the stratification interface descends during the initial filling phase, reaching a maximum depth of penetration $\left(\widehat{z}_{\text {over }}\right)$ before ascending back up to the steady-state location $\left(\widehat{z}_{\mathrm{ss}}\right)$. In the results presented, the stratification interface tends towards the same steady-state interface height for a given doorway aspect ratio regardless of the doorway height [2]. By reducing the relative doorway height, the depth of penetration is increased along with the time scale required to reach steady-state.

In Fig. 7b, the non-dimensional ventilation flow rate and plume flow rate at the stratification interface is plotted as a function of non-dimensional time for $h_{\mathrm{d}}=1$ and $0.5(R=2)$. Both sets of results show that the ventilation flow varies much more gradually than the plume flow. When the flow reaches steady-state, the ventilation flow rate matches the plume flow rate at the stratification interface. This occurs during the initial filling process as the stratification interface height overshoots the steady-state location. However, at this point the buoyancy in the upper layers continues to increase (see Fig. 7c), leading to an increase in ventilation flow rate (see Eq. (11)). Following this, the stratification interface then ascends back up towards the steady-state height.

In Fig. 7c, the non-dimensional mean buoyancy is plotted as a function of non-dimensional time for $h_{\mathrm{d}}=1$ and $0.5(R=2)$. Reduction in the relative doorway height leads to a more gradual variation in mean buoyancy. As a consequence, the ventilation flow rate varies much more slowly (see Fig. 7b) and the stratification interface penetrates deeper into the room (see Fig. 7a).

In Fig. 7d, the steady-state stratification interface height (calculated using Eq. (15)) and the maximum overshoot height for
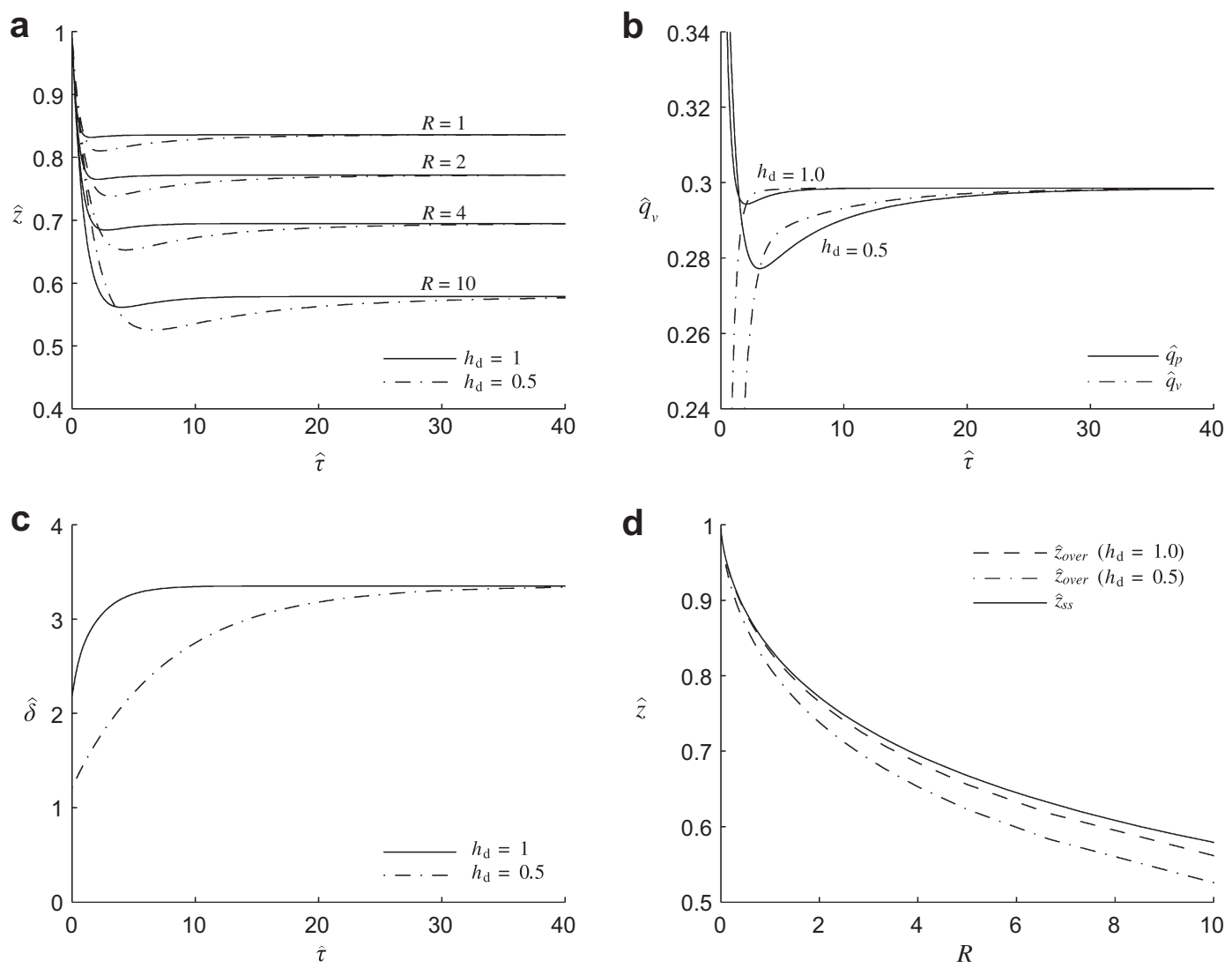

Fig. 7. Results obtained using the mathematical model to investigate the effect of changing doorway aspect ratio $R$ and relative doorway height $h_{\mathrm{d}}$. 
$h_{\mathrm{d}}=0.5$ and 1 are plotted as a function of the doorway aspect ratio. As may be expected from Eq. (15), the steady-state stratification interface height is reduced as the aspect ratio is increased. A similar trend is observed for the overshoot stratification interface height. These results show that increasing the doorway aspect ratio increases overshoot depth $\left(\widehat{z}_{\text {ss }}-\widehat{z}_{\text {over }}\right)$. Further to this, the effect of reducing the relative doorway height $\left(h_{\mathrm{d}}\right)$ increases further the depth that the initial flow overshoots.

We have also performed simulations with a two-layer version of this model [26]. This was based on the two-layer displacement-ventilation model [5], suitably changed to include doorway flows (rather than displacement ventilation) in a way similar to that detailed here. Comparison between model predictions using the stratified and the two-layer models shows that the stratified model leads to greater overshoot during the initial transient flow and longer time scales to achieve a steadystate. Again, as for the displacement-ventilation flow, this was due to the way in which the buoyancy above the stratification interface was modelled.

\section{Summary and conclusions}

In this paper we have presented a new mathematical model for buoyancy-driven ventilation provided by: $i$ ) displacement ventilation; and ii) open doorway(s). It is based on the filling-box model proposed by Germeles [16] and uses the turbulent plume equations to model the filling process. Approaches similar to those of Linden et al. [1] and Phillips and Woods [2] were used to model displacement ventilation and doorway ventilation respectively. Reduced-scale experiments were conducted both to develop and to validate the model, where saline solution and fresh water was used to provide density differences.

Using a series of images obtained during an experiment (Section 3), a description of the two-layer filling produced by a buoyant source ventilated by an open doorway was given. During the initial transient flow before the upper layer reached the top of the doorway, a filling-box flow ensued. As the layer deepened, some of the buoyant fluid was exchanged through the doorway. The upper layer continued to deepen, eventually reaching a steady-state. In this experiment, a circulatory flow was set up in the lower layer produced by the flow that entered the room. This flow disturbed the plume, displacing some of the buoyant fluid onto the stratification interface. This effect was not observed in experiments where two doorways were used and it was commented that this is perhaps due to both the location and the aspect ratio of the doorway(s).

In modelling the ventilation provided by an open doorway, it is necessary to calculate the exchange interface height. This depends on the location of the stratification interface and in this paper we proposed a new approximation linking the stratification and exchange interface heights. In comparing the mathematical model with the experiments, it was found that the new approximation significantly improved tracking of the stratification interface. We also presented a comparison between the new mathematical model and the experiments in terms of the temporal evolution of the vertical buoyancy profile. Although in some cases there was some discrepancy between the experimental results, there was generally a very good agreement between the mathematical modelling and experimental results.

We also used the mathematical model to investigate the transient filling of a room for other configurations. For doorway ventilation, Phillips and Woods [2] showed that the stratification interface depends on the aspect ratio of the doorway and is independent of the source buoyancy flux. However, during the initial transient filling, the stratification interface height may overshoot this steady-state location. In these investigations we found that the amount that the flow overshoots depends on both the doorway aspect ratio and the height of the doorway in relation to the height of the room. In this investigation, it was found that the flow overshoots more significantly when the height of the doorway is reduced compared to the height of the room.

\section{Acknowledgements}

This work was supported by EPSRC grant GR/R69037/01.

\section{Appendix}

In this appendix we show that the momentum flux is dependent on the doorway aspect ratio, the source buoyancy flux, the doorway height and the location of the plume virtual origin. To investigate these relationships, we formulate an expression for the ventilation momentum flux in terms of these parameters. Assuming a uniform velocity, the ventilation momentum flux $M_{\mathrm{v}}$ is dependent on the flow area and the ventilation flow rate:

$M_{\mathrm{v}}=\frac{\widehat{Q}_{\mathrm{s}}^{2}}{W H_{\mathrm{d}}} \frac{\widehat{q}_{\mathrm{v}}^{2}}{\left(\widehat{z}_{\text {int }}-\widehat{z}_{0}\right)}$,

where $\widehat{Q}_{S}$ is the volume flow rate scale defined in Eqs. (1) (rescaled to the doorway height $Z_{\mathrm{s}}=H_{\mathrm{d}}$ ). Substituting for the volume flow rate using Eq. (11) and non-dimensionalising, this becomes:

$\widehat{m}_{\mathrm{v}}=\frac{M_{\mathrm{v}}}{\widehat{M}_{\mathrm{s}}}=C_{\mathrm{en}}^{-3 / 2}\left(\frac{\widehat{\delta} \widehat{f}}{\widehat{z}_{\text {int }}-\widehat{z}_{0}}\right) R^{-1}$,

where

$\widehat{M}_{\mathrm{s}}=\left[C_{\mathrm{en}}^{3 / 2} H_{\mathrm{d}}^{2}\right]^{-1} \widehat{Q}_{\mathrm{s}}^{2}$

is the momentum flux scale (again scaled on the doorway height) and $\widehat{m}_{\mathrm{v}}$ is the dimensionless momentum flux of the ventilation flow. Written in this non-dimensional form, the vertical length scale and source buoyancy flux are included in the momentum scale $\widehat{M}_{\mathrm{s}}\left(\propto H_{\mathrm{d}}^{4 / 3} B_{0}^{2 / 3}\right)$. For a given aspect ratio and plume virtual origin height, these terms simply scale the magnitude of the momentum flux.

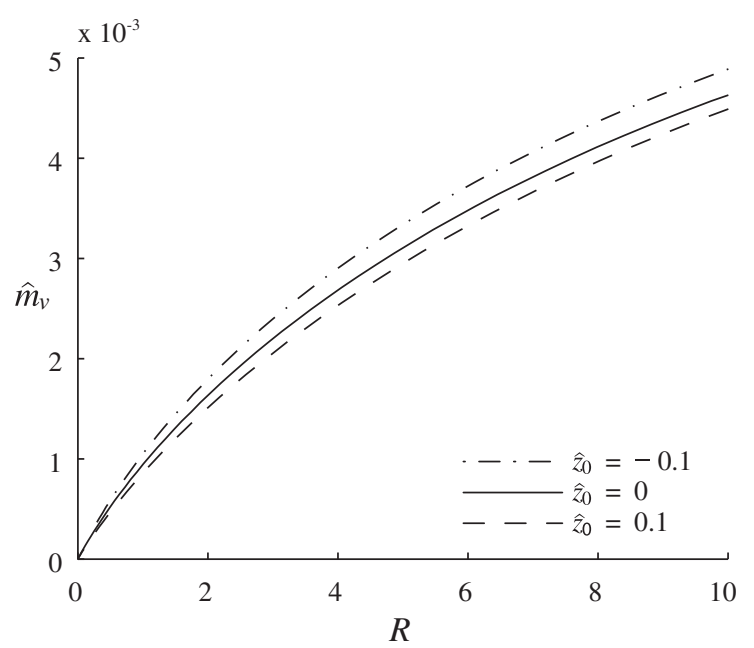

Fig. A1. Non-dimensional momentum flux as a function of doorway aspect ratio. 
Eq. (A2) shows that the momentum flux is: $i$ ) proportional to the mean buoyancy of the upper layers $\widehat{\delta}$ and the function $\widehat{f}$; and $i i)$ inversely proportional to the relative depth of the inflowing ventilation $\left(\widehat{z}_{\text {int }}-\widehat{z}_{0}\right)$ and aspect ratio $R$. For a given configuration, $R$ is constant, and during the filling phase, $\widehat{\delta}$ and $\widehat{f}$ increase whereas $\widehat{z}_{\text {int }}$ is reduced. The overall effect is an increase in the non-dimensional momentum flux. Once the flow reaches steady-state, these terms are constants that depend on the aspect ratio. Using the steady-state two-layer model [2], Eq. (A2) was evaluated for $\widehat{z}_{0}=-0.1,0$ and 0.1 and $R<10$ (see Fig. A1). This figure shows that increasing the doorway aspect ratio leads to an increase in the momentum flux. This is perhaps unexpected, as the momentum flux is inversely proportional to the aspect ratio (see Eq. (A2)). However, as the remaining terms are dependent on the aspect ratio and the product of these terms increases more rapidly than $R^{-1}$ reduces, the overall effect is an increase in the momentum flux. These results also show that the height of the floor with respect to the virtual origin also modifies the ventilation momentum flux.

\section{References}

[1] Linden PF, Lane-Serff GF, Smeed DA. Emptying filling boxes: the fluid mechanics of natural ventilation. Journal of Fluid Mechanics 1990;212: 309-35.

[2] Phillips JC, Woods AW. On ventilation of a heated room through a single doorway. Building and Environment 2004;39:241-53.

[3] Dalziel SB, Lane-Serff GF. The hydraulics of doorway exchange flows. Building and Environment 1991;26:121-35.

[4] Li Y, Sandberg M, Fuchs L. Effects of thermal radiation on airflow with displacement ventilation: an experimental investigation. Energy and Buildings 1993;19:263-74.

[5] Kaye NB, Hunt GR. Time-dependent flows in an emptying filling box. Journal of Fluid Mechanics 2004;520:135-56.

[6] Bruce J. Natural ventilation: its role and application in the bio-climatic system Farm Building R\&D Studies 1977;8:1-8.

[7] Bruce J. Natural convection through openings and its application to cattle building ventilation. Journal of Agricultural Engineering Research 1978;23: 151-67.

[8] Gladstone C, Woods AW. On buoyancy-driven natural ventilation of a room with a heated floor. Journal of Fluid Mechanics 2001;441:293-314.
[9] Li Y. Buoyancy-driven natural ventilation in a thermally stratified one-zone building. Building and Environment 2000;35:207-14.

[10] Mundt E. Convection flows above common heat sources in rooms with displacement ventilation. In: Proceedings of Roomvent '90, the second international conference on air distribution in rooms, Oslo, Norway; 1990.

[11] Gao J, Zhao JN, Gao FS. Displacement of natural ventilation in an enclosure with a convective/radiative heat source and non-adiabatic envelopes. Journal of Solar Energy Engineering - Transactions of the ASME 2006;128: 83-9.

[12] Sandbach SD, Lane-Serff GF. Transient buoyancy-driven ventilation: Part 2. Modelling heat transfer. Building and Environment 2011;46(8):1589-99.

[13] Hunt GR, Linden PF. Steady-state flows in an enclosure ventilated by buoyancy forces assisted by wind. Journal of Fluid Mechanics 2001;426:355-86.

[14] Cenedese C, Dalziel SB. Concentration and depth fields determined by the light transmitted through a dyed solution. In: Proceedings of the 8th international symposium on flow visualization, Sorrento, Italy, 1998.

[15] Worster MG, Huppert HE. Time-dependent density profiles in a filling box. Journal of Fluid Mechanics 1983;132:457-66.

[16] Germeles AE. Forced plumes and mixing of liquids in tanks. Journal of Fluid Mechanics 1975;71:601-23.

[17] Coffey CJ, Hunt GR. On the night purging of naturally ventilated enclosures the effect of the relative area of openings. In: Gamerio Da Silva MC, editor. Proceedings of Roomvent '04, the ninth international conference on air distribution in rooms, Coimbra, Portugal; 2004.

[18] Morton BR. Forced plumes. Journal of Fluid Mechanics 1959;5:151-63.

[19] Hunt GR, Kaye NB. Virtual origin correction for lazy turbulent plumes. Journal of Fluid Mechanics 2001:435:377-96.

[20] Mundt E. Displacement ventilation systems - convection flows and temperature gradients. Building and Environment 1995;30:129-33.

[21] Morton BR, Taylor GI, Turner JS. Turbulent gravitational convection from maintained and instantaneous sources. Proceedings of the Royal Society 1956;A234:1-23.

[22] Borutzky W, Barnard B, Thoma J. An orifice flow model for laminar and turbulent conditions. Simulation Modelling Practice and Theory 2002;10: $141-52$.

[23] Merritt HE. Hydraulic control systems. John Wiley and Sons; 1967.

[24] Holford JM, Hunt GR. The dependence of the discharge coefficient on the density contrast - experimental measurements. In: Proceedings of the fourteenth Australasian fluid mechanics conference, Adelaide University, Adelaide, Australia; 2001. p. 123-6.

[25] Hunt GR, Holford JM. The discharge coefficient - experimental measurement of a dependence on density contrast. In: Proceedings of the 21st AIVC conference, The Hague, Netherlands; 2000.

[26] Sandbach SD. Mathematical and laboratory modelling of ventilation. The University of Manchester, PhD thesis; 2009.

[27] Dalziel SB. Two-layer hydraulics: a functional approach. Journal of Fluid Mechanics 1991;223:135-63. 